\title{
DE KLEDING VAN WAYANGPOPPEN
}

Museum Volkenkunde heeft sinds juni van dit jaar de nieuwe Indonesië-zaal geopend. De prachtig bewerkte stenen beelden uit de hindoe-boeddhistische tempel van Singosari, Oost-Java, uit de $13^{\mathrm{e}}$ eeuw vormen het hoogtepunt van de vernieuwde zaal. Naast de vele beelden en attributen is er meer aandacht voor de Indonesiërs zelf. Hun levensgewoonten en gebruiken worden op wandvullende projecties indrukwekkend in beeld gebracht. Ook de bekende 'Lombokschatten' zijn nu te bewonderen in grote vitrinekasten.

Geheel nieuw in de zaal is een bijzondere collectie poppen die in 1893 speciaal voor koningin Wilhelmina in Indonesië werd gemaakt. Later werd de collectie geschonken aan Museum Volkenkunde. De poppen vertegenwoordigen de Indonesische bevolkingsgroepen die eind $19^{\mathrm{e}}$ eeuw onder Nederlands gezag stonden, en vormen daardoor een uniek historisch document. In de kleding, die tot in het kleinste detail is uitgewerkt, wordt de identiteit van de dragers uitgedrukt, onder andere doordat de invloed van islam en christendom wordt getoond. In de vaste opstelling van het museum bevinden zich (platte en driedimensionale) wayang-poppen.

Wayang-poppen beelden meestentijds edelen uit, maar ook goden, clowns, bedienden en demonen om verschillende verhalen weer te geven. Met dit artikel wil ik ingaan op de mate waarin poppenmakers rekening hielden met de betekenis van de doeken en patronen wanneer zij de poppen aankleedden. Daarbij kijk ik naar de kleding van de houten driedimensionale wayang golek poppen en dan met name de rokken, kaïns, die zij dragen. Deze rokken zijn vaak gemaakt van batik, van egaal gekleurde zijde of van katoen met een streep- of ruitpatroon (lurik).

\section{Wayang golek}

Bij wayang denkt men meestal direct aan het Midden-Javaanse schaduwspel dat gespeeld wordt met platte leren poppen, het zogeheten wayang kulit, waarbij gebruik wordt gemaakt van een scherm waarop de schaduwen van de poppen worden geprojecteerd. Echter, er zijn meerdere varianten van wayang, zoals wayang golek, het poppenspel dat gebruik maakt van houten driedimensionale poppen die direct te zien zijn. ${ }^{1}$ Deze vorm is vooral populair in Sunda, West-Java.

Binnen wayang golek kan nog een onderscheid gemaakt worden tussen wayang golek purwa, wayang golek cepak en wayang golek menak. Onder wayang golek purwa vallen de verhalen gebaseerd op de klassieke Indiase epos: het Mahabharata en het Ramayana. Wayang golek cepak beeldt verhalen uit van heldendichten over prins Panji en Damar Wulan. ${ }^{2}$ De verhalen van de wayang golek menak hebben een Perzische afkomst en houden verband met de komst ${ }_{07 \mathrm{AM}}$ van de Islam. Onder dit repertoire vallen de avonturen van Amir Hamzar. ${ }^{3 e}$ access 
Afbeelding 2

Semar met een parang rusak kain, hout en

katoen, h. $49 \mathrm{~cm}$.,

Cirebon, 1929-1930,

Museum Volkenkunde, inv.nr. 2716-17.

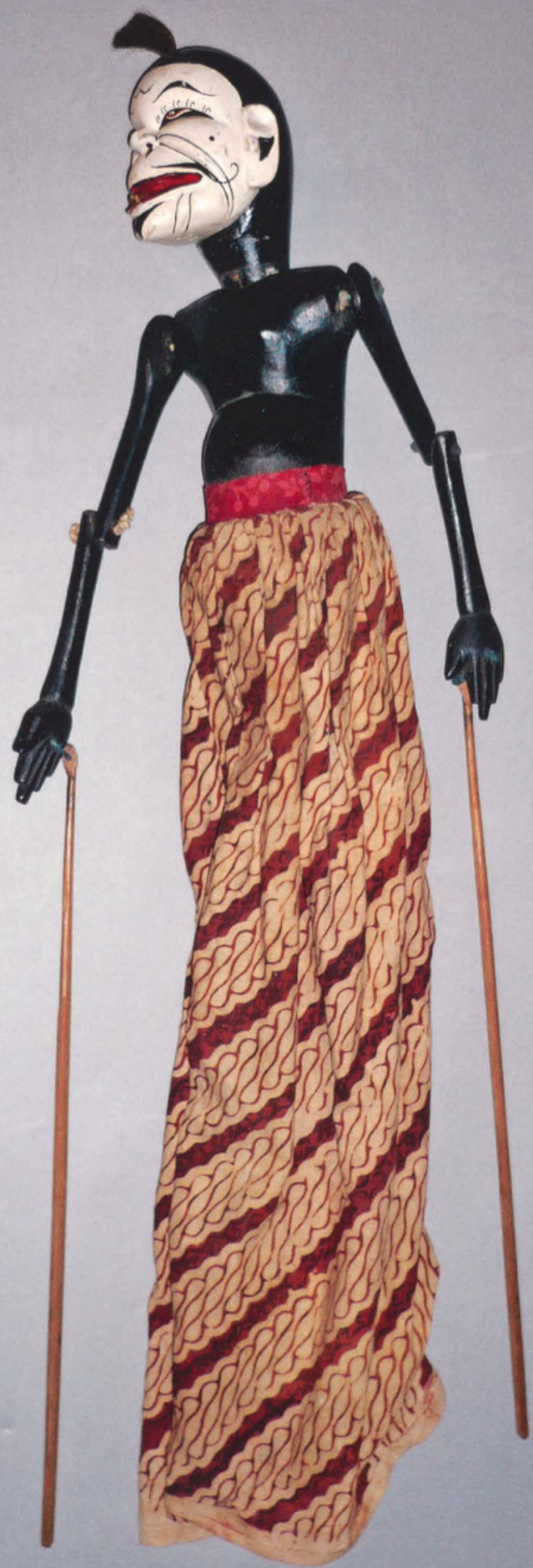

Downloaded from Brill.com04/26/2023 09:17: ๑7AM 
De eerste geschreven verwijzingen naar wayang golek in West-Java zijn volgens Peter Buurman gevonden in de $15^{\mathrm{e}}$ eeuw. ${ }^{4}$ Andere bronnen vermelden dat wayang golek in 1583 in Kudis, Midden-Java, geïntroduceerd werd door Sunan Giri, de eerste Islamitische wali (geestelijk leider). ${ }^{5}$ Deze eerste golek poppen waren gemaakt om de oude heldendichten over prins Panji en Damar Wulan uit te beelden. Zij waren dus onderdeel van het wayang golek cepak repertoire. Later werden ze ook gebruikt voor de menak verhalen. De wayang golek purwa is pas in de $19^{\mathrm{e}}$ eeuw ontstaan toen een aantal regenten in West-Java poppensnijders uit Tegal, Midden-Java, verzocht golek poppen te maken om de purwa verhalen mee te vertonen. De iconografie van de wayang golek purwa poppen is gebaseerd op de wayang kulit karakters omdat de poppensnijders wayang kulit poppen als uitgangspunt voor de houten poppen gebruikten. ${ }^{6}$

\section{Batik kaïns voor verschillende bevolkingsgroepen}

De basis van de poppenkleding was vaak van batik. Elk batikpatroon impliceerde een eigen sociaaleconomische status. Het gewone volk moest genoegen nemen met patronen van strepen en ruiten, lurik. ${ }^{7}$ De elite ging gekleed in andere motieven. Vorsten en hun familie, vooral aan de hoven van Yogyakarta en Surakarta, waren gehuld in de zogeheten verboden patronen. ${ }^{8}$ Onder deze patronen vallen: parang rusak - een motief met schuine, bruine strepen op een witte ondergrond; sembagen hok - bloem- en bladornamenten met in het midden een medaillon met een gebogen vogelfiguur. Ook alle semen patronen behoorden alleen de vorsten, hun vrouwen, zonen en dochters toe. ${ }^{9}$

In de wayang golek collectie van Museum Volkenkunde dragen de poppen uiteenlopende batik kaïns. De meeste poppen beelden edelen uit en kunnen dan ook batik doeken dragen met een van de bovenbeschreven patronen. Maar soms is een pop die geen edele uitbeeldt, en dus niet een van de verboden patronen mag dragen, toch hiermee gekleed, zoals Semar (afb. 2). Deze pop komt uit Cirebon waar de mensen niet spraken van verboden patronen. ${ }^{10}$

Semar, Petruk, Gareng en Cepot, de vier bekende bedienden van de helden uit de verschillende verhalen, worden beschouwd als de voorouders van de Javanen. Zij behoren tot het 'gewone' volk. Doordat deze poppen vooral lurik doeken dragen, is een statussysteem aan de patronen af te lezen. Semar zou in de regio's van Yogyakarta en Surakarta geen parang rusak patroon dragen, maar slechts een lurik kaïn (afb. 1).

\section{Lurik voor de bedienden}

Over het algemeen worden poppen die bedienden uitbeelden vooral gekleed in een kaïn met lurikpatronen. Dit is ook te zien in de collectie van Museum Volkenkunde waar de bedienden, met uitzondering van Semar, een lurik kaïn dragen. Lurik is een geweven doek, simpel van uiterlijk en technisch eenvoudig vervaardigd. Zowel de traditionele horizontaal en verticaal gestreepte doeken als de traditioneel geruite doeken worden lurik genoemd. ${ }^{11}$ Deze doeken worden door heel Indonesië gevonden, maar de term lurik wordt slechts in Centraal- en Oost-Java gebruikt. Bij het maken van lurik doeken wordt nogal eens gebruik gemaakt van andere weeftechnieken, zoals $i k a t, 2023$ 09:17:07 AM 
Afbeelding 3 (pag. 29) Arjuna met een lurik kain, hout en textiel, h. $52 \mathrm{~cm}$., Yogyakarta, midden $19^{\circ}$ eeuw, Museum Volkenkunde, inv.nr. 300-602. waarbij de draden voor het weven in een patroon worden geverfd, door het plaatselijk afbinden van de draden, en songket, een weeftechniek waarbij vaak zijden stoffen worden versierd met gouddraad. ${ }^{12}$

Hoewel lurikdoeken slechts uit strepen en ruiten bestaan hebben zij alle een betekenis en vormen ze een wezenlijk onderdeel van de Javaanse traditie, vooral in de regio's van Solo en Yogyakarta, waar het geloof wordt aangehangen dat de gestreepte doeken magische krachten bezitten. Dit is nog terug te zien in de rituelen waarvoor de lurik doeken gebruikt worden. Zo staat het regenboogmotief met zijn brede, kleurrijke strepen, kluwung, symbool voor het wonder van de natuur en het goddelijke. Doeken met dit motief worden gebruikt om kwaadaardige krachten af te weren. Zij spelen een belangrijke rol in bruiloftrituelen of ter bevordering van een voorspoedige zwangerschap. ${ }^{13}$ Naast de patronen hebben ook kleuren bij lurik grote betekenis. Met de kleuren van de vier windrichtingen wordt de cyclus van het menselijk leven symbolisch weergegeven. Wit, symbool voor geboorte, is de kleur van het oosten; rood, de kleur van het volwassen leven, representeert het zuiden; geeloranje is de kleur van rijpheid, en hoort bij het westen; zwart staat symbool voor de dood en hoort bij het noorden. Daarnaast bestaan kleurcombinaties met een eigen symbolische betekenis. ${ }^{14}$ Een veel gebruikte kleurcombinatie is zwart-wit; dit contrast houdt verband met het idee van kosmische totaliteit met het licht van de dag tegenover het donker van de nacht. ${ }^{15}$ Deze doeken worden beschouwd als symbool om kwade krachten tegen te gaan. Het dragen ervan zou bescherming bieden tegen slechte invloeden en ongeluk. ${ }^{16}$

De bedienden in de poppencollectie van Volkenkunde dragen vooral deze patronen van licht en donker, vaak zwart en wit. Veelal zijn de kaïns geruit, maar in andere gevallen worden de contrasten weergegeven in verticale strepen.

Tegenwoordig worden de bediendenpoppen ook wel gekleed in het kawung patroon wat iets wegheeft van gestileerde bloemen. De naam komt waarschijnlijk van de gelijkenissen die dit patroon vertoont met doorgesneden zaden van de arenpalm, welke ook kawung worden genoemd. Dit motief wordt gemaakt met de batiktechniek en is vooral in Yogyakarta zeer geliefd. ${ }^{17}$

\section{Effen kaïns voor de meest edelen}

In de kleding van de poppen wordt de status van de dragers uitgedrukt. Waar bedienden doorgaans gekleed zijn in lurik, zouden de edele poppen uit de wayang golek purwa gekleed gaan in batik motieven. Toch wordt tegenwoordig steeds vaker gebruik gemaakt van een effen gekleurde, zijden kaïn voor de meest edele mannen en vrouwen. Alleen voor de poppen die vervaardigd zijn voor de toeristenmarkt wordt van deze regels afgeweken. ${ }^{18}$ In dit geval dragen alle edelen batik kaïns. Echter, ook in de Volkenkundecollectie zien we afwijkingen. Slechts een klein aantal edele poppen draagt een 'correcte' kaïn; egaal gekleurd en van zijde. Sommige edelen hebben een kaïn met een lurik patroon, zoals Arjuna, een van de Pandawabroers uit het Mahabharata verhaal en een van de meest edele personen (afb. 3). Deze pop komt uit Yogyakarta, dus eigenlijk zouden we een dergelijke pop verwachten met een batik kaïn of, als hij helemaal naar de regels gekleed zou worden, met een effen kaïn. Voorts zijn niet alle edelen al dragen zij effen gekleurde kaïns gehuld in zijde, soms dragen zij een,kaïn van effen katoen. Het lijkt : 17:07 AM aannemelijk dat voor wayang golek poppen niet altijd de relatief duré en ${ }^{\text {e }}$ access 


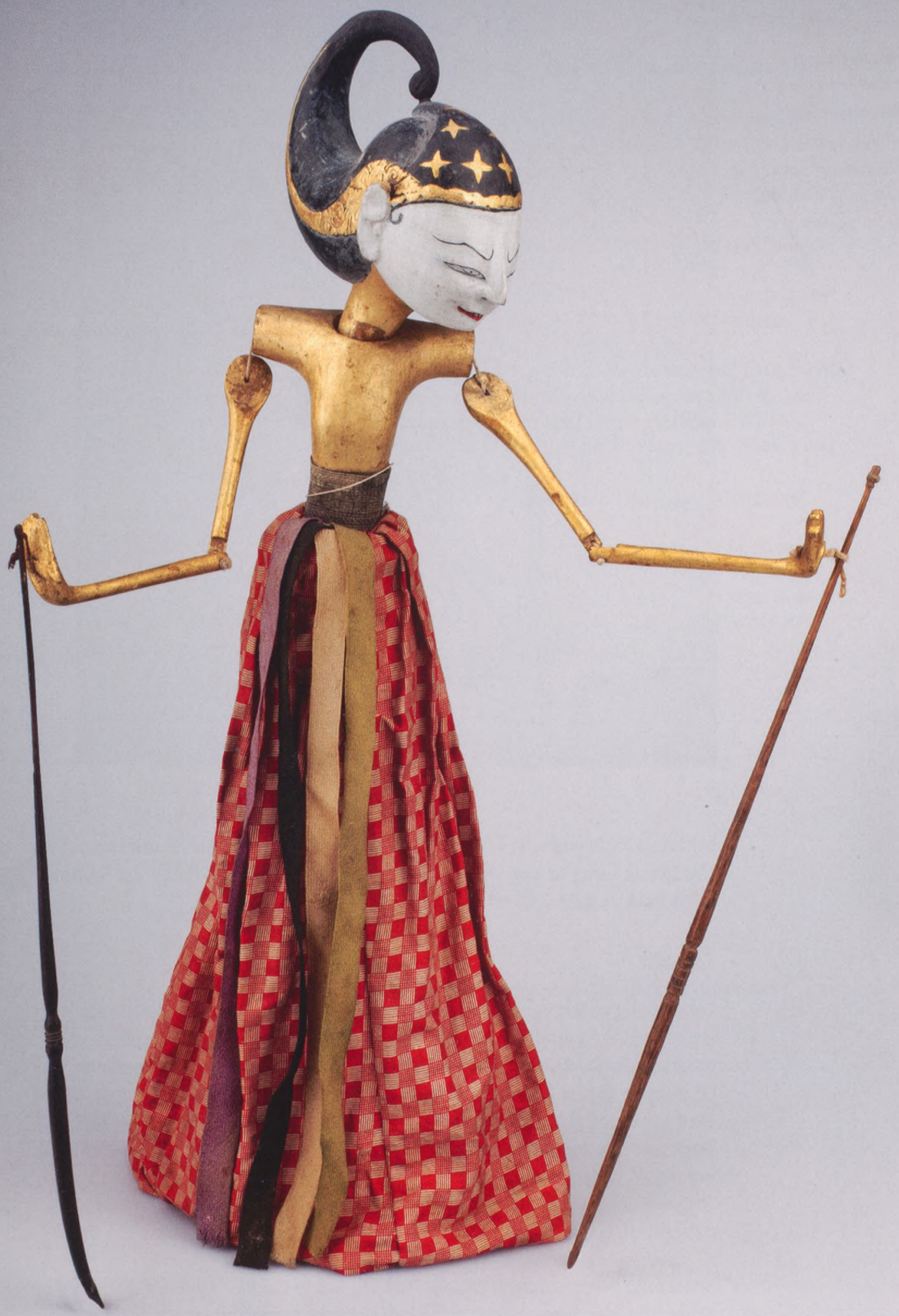


Afbeelding 4

Niet-edele man met effen kain, hout en textiel, h. $44 \mathrm{~cm}$., Java, vroeg $20^{\circ}$ eeuw, Museum Volkenkunde, inv. nr. 3155-190.

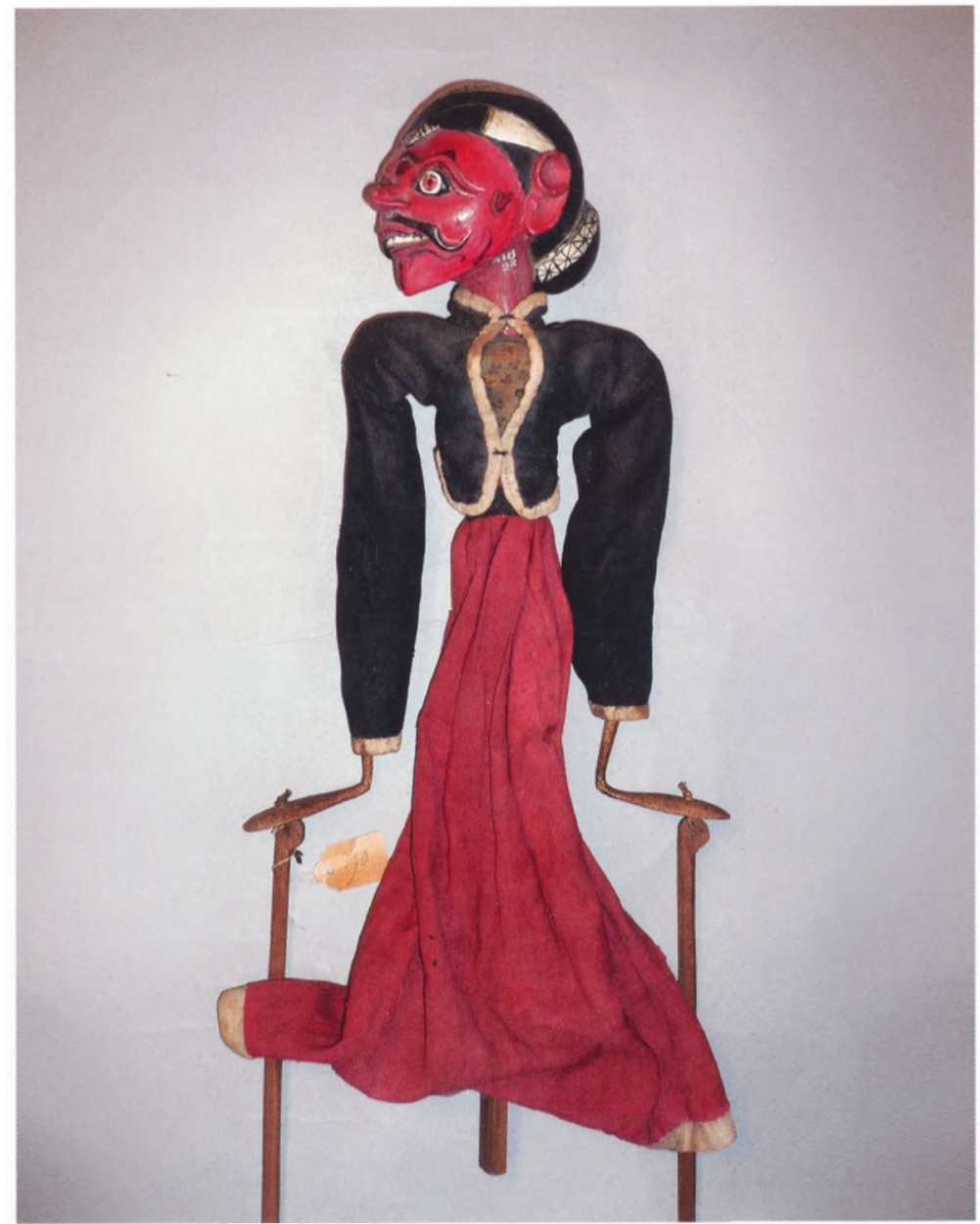

schaarse zijde gebruikt kon worden. De regels werden dus flexibel toegepast. Dat is ook terug te zien in de kleding van de niet-edele poppen die toch een effen kaïn dragen (afb. 4).

\section{Tot slot}

De wayang golekpoppen in Museum Volkenkunde zijn niet alleen prachtig om te zien, ze vertellen ons ook veel over hoe batik en lurik specifiek voor diverse bevolkingsgroepen werden gebruikt. De kleding en de patronen van de poppen tonen aan hoe de verschillende Indonesische bevolkingsgroepen eind $19^{\mathrm{e}}$ eeuw gekleed gingen volgens cultureel bepaalde voorschriften. Toch werden sommige kledingvoorschriften met flexibiliteit en creatief denkvermogen toegepast. $U$ kunt het met eigen ogen aanschouwen bij een volgend bezoek aan de nieuwe Indonesië-zaal in Museum Volkenkunde dat raad ik $u$ van harte aan.

Samantha Bloem studeert Indonesian Studies in Leiden. Tijdens haar stage bij Museum Volkenkunde heeft zij zich gericht op de kleding van de wayang golekpoppen en dan met name op het lurikpatroon op derokken $\triangle$ De wayang 17 : $97 \mathrm{Am}$ golekpoppen vormen het onderwerp van haar masterscriptie. 
Peter Buurman, Wayang golek: de fascinerende wereld van het klassieke West-Javaanse poppenspel, A.W. Sijthoff, Alphen aan den Rijn, 1980.

Nian S. Djoemena, Lurik: garis-garis bertuah/Lurik: the magic stripes, Djambatan, Jakarta, 2000.

Bambang Harsrinuksmo, et al., Ensiklopedi wayang Indonesia, Sena Wangi, Jakarta, 1999.

Renske Heringa, Function and meaning of batik-lurik: a reconstruction', in: Michael Hitchcock en Wiendu Nuryanti (eds.), Bullding on batik: the globalization of a craft community, Ashghate, Aldershot, 2000, pp. 51-63.

David Irvine, Leather gods \& wooden heroes: Java's classical wayang, Times Editions, Singapore, 1996.

Johan Ernst Jasper en Mas Pirngadie, De inlandse kunstnitverheld in Nederlands-Indie, 3: de batikkunst, De Boek en Kunstdrukkerij van Mouton \& Co, 's Gravenhage, 1916.

Fiona Kerlogue, The book of batik, Editions Didier Millet, Singapore, 2004.

Susan MacMillan Arensberg, Javanese battks, Museum of Fine Arts, Boston, MA, 1978.

Wahyono Martowikirdo, 'Beberapa catatan tentang lurik. Notes upon lurik', in: MarieLouise Nabholz-Kartaschoff, Ruth Barnes en David J. Stuart-Fox (eds.), Weaving patterns of life: Indonesian textlle symposium 1991, Basel, 1993, pp. 335. [Museum of Ethnography]

Friedrich M. Seltmann en Werner Gamper, Stabpuppensplel auf Java: wayang golek, Offsetdruckerei Konrad Kyburz, Dielsdorf, 1980.

Alit Veldhuizen-Djajasoebrata, Batik op Java, Museum voor Land- en Volkenkunde, Rotterdam, 1972.

Andrew N. Weintraub, Power plays: wayang golek puppet theater of West Java, Ohio University Research in International Studies, Athens, Institute of Southeast Asian Studies, Singapore, 2004.

\section{Noten}

*Foto's afbeelding 3 en 6: Museum Volkenkunde. Overige foto's: de auteur.

1 Buurman 1980: 11.

2 Buurman 1980: 15.

3 Seltmann en Gamper 1980: 39.

4 Buurman 1980: 15.

5 Harsrinuksmo 1999: 597; Weintraub 2004: 28

6 Weintraub 2004: 28.

7 Heringa 2000: 51-2.

8 Jasper en Mas Pirngadie 1916: 227.

9 Zie Jasper en Mas Pringadie voor een overzicht van alle verboden patronen.

10 MacMillan Arensberg 1978: 19.

11 Djoemena 2000: 31.

12 Veldhuizen-Djajasoebrata 1972: 54; Kerlogue 2004: 35; Martowikirdo 1993: 335.

13 Djoemena 2000: 54-5.

14 Djoemena 2000: 28-30.

15 Heringa 2000: 56.

16 Djoemena 2000: 29.

17 Veldhuisen-Djajasoebrata 1972: 17.

18 Buurman 1980: 27. 


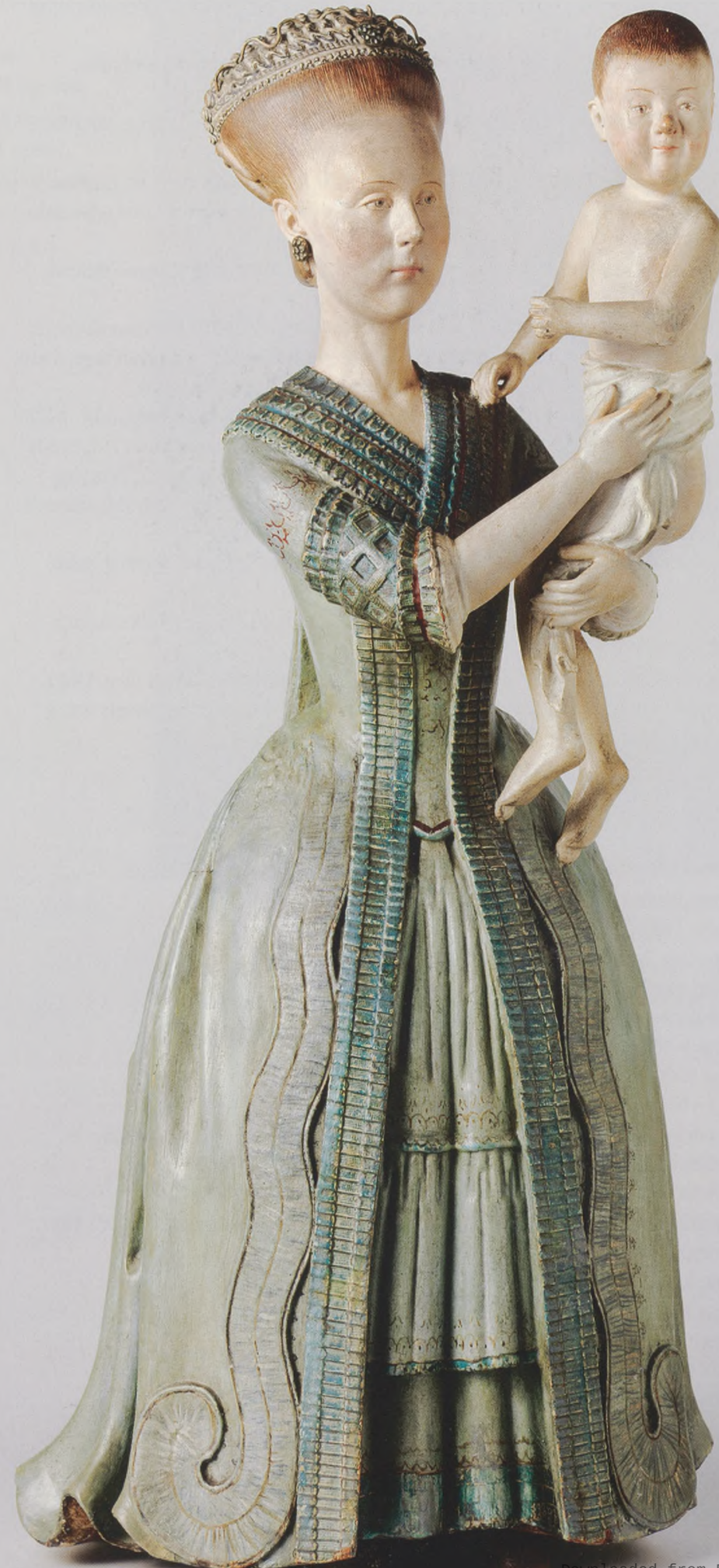

